\title{
DOME OSTEOTOMY OF THE TIBIA FOR OSTEOARTHRITIS OF THE KNEE
}

\author{
N. A. SUNDARAM, J. P. HALlETT, M. F. SULlivaN \\ From the Royal National Orthopaedic Hospital, London
}

\begin{abstract}
Proximal tibial osteotomy is commonly performed for osteoarthritis of the knee with deformity. The results of 105 dome osteotomies have been reviewed at a minimum follow-up of one year and an average of 4.8 years.

Before operation all the knees were painful, $50.5 \%$ severely; a further $45.7 \%$ disturbed sleep at night. At review $15.2 \%$ of knees were free of pain and $60 \%$ had only slight pain which did not restrict activity. The preoperative range of movement was maintained and there was only a slight tendency for radiological changes to progress, with actual improvement in some cases.

No correlation was found between the correction of deformity to physiological valgus and the result. We cannot explain why tibial osteotomy produces such useful and sustained pain relief.
\end{abstract}

Upper tibial osteotomy is one of the standard operations for painful osteoarthritis of the knee, and accurate correction of any associated deformity is usually thought to be important. Tibial osteotomies for osteoarthritis have been practised in the United Kingdom since the early 1900s (Wardle 1964), but became more popular after Jackson and Waugh reported their results in 1958 and 1961. The success of the operation has been thought to derive from factors similar to those which apply in upper femoral osteotomy for osteoarthritis of the hip. These include mechanical realignment, the use of a different and more congruous contact area in the joint, release of tension from stretched capsule and soft tissues, and the reduction of intra-osseous venous engorgement. In the longer term fibrocartilage may form on the worn articular surface.

Brackett described dome osteotomy of the proximal femur to treat an ununited fracture of the neck of the femur (Magnuson and Stack 1949, pp 275-83). Jackson and Waugh (1961) found "ball and socket" osteotomy was most satisfactory at the level of the tibial tubercle, and in 1974 they reported 16 dome operations in a series

N.A. Sundaram, MCh Orth, FRCS, FRCS Ed(Orth), Senior Orthopaedic Registrar

Mersey General Hospital, Latrobe, Tasmania 7307, Australia.

J. P. Hallett, MA, FRCS, Consultant Orthopaedic Surgeon Ipswich Hospital, Ipswich, Suffolk IP4 5PD, England.

M.F. Sullivan, MA, FRCS, Consultant Orthopaedic Surgeon

Royal National Orthopaedic Hospital, Brockley Hill, Stanmore, Middlesex HA7 4LP, England.

Requests for reprints should be sent to Mr J. P. Hallett.

(C) 1986 British Editorial Society of Bone and Joint Surgery $0301-620 \mathrm{X} / 86 / 5108 \$ 2.00$ of 226 upper tibial osteotomies, but at that time they preferred wedge osteotomies. Maquet's technique of barrel vault osteotomy (1976) has been described in detail by Krempen and Silver (1982), who reported the results in 40 patients.

We have assessed the results of upper tibial dome osteotomy, an operation commonly performed at the Royal National Orthopaedic Hospital.

\section{TECHNIQUE OF OPERATION}

We describe a method of performing the operation which has been found to be satisfactory. The planned angular correction is derived from the measurement of angles on standing radiographs taken on long films. The operation is performed under general anaesthesia with a pneumatic tourniquet inflated after exsanguination of the leg.

The fibula is divided to allow adequate correction of the tibia; this can be done safely, avoiding damage to the common peroneal nerve or its branches, by excising about $1.5 \mathrm{~cm}$ from the mid-shaft through a separate incision. The tibial osteotomy can be performed easily through a midline vertical incision extending distally about $12 \mathrm{~cm}$ from the lower pole of the patella. The knee is flexed to $90^{\circ}$, the patellar tendon is cleared and periosteum and muscles are stripped from the upper tibia, passing bone levers in contact with the bone to protect posterior structures.

A curved line is marked on the bone with its dome just above the tibial tuberosity (Fig. 1) and a series of $3 \mathrm{~mm}$ drill holes are made along this line, just penetrating the posterior cortex. They are close to each other and are at right angles to the long axis of the bone. Two stout 


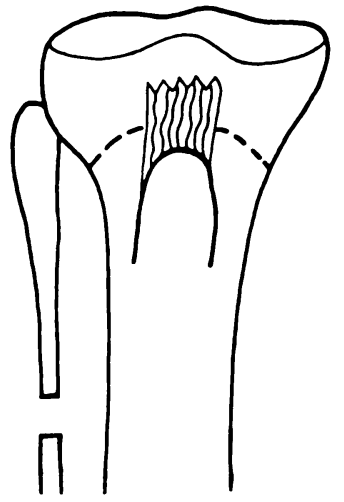

Fig. 1

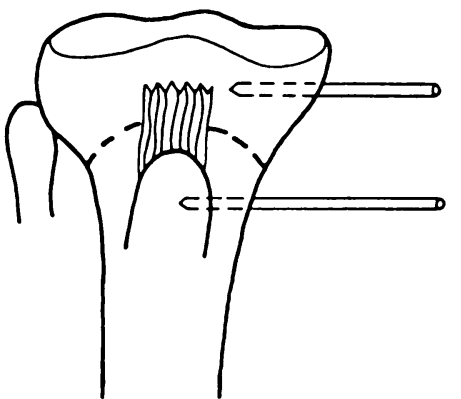

Fig. 2

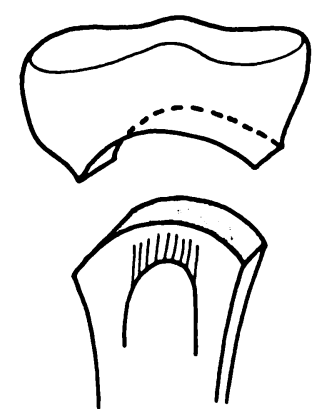

Fig. 3

Surgical technique of upper tibial dome osteotomy showing, from left to right, the sites of the osteotomies, pins placed to check alignment, the shape of the tibial osteotomy (separation exaggerated), and the displacement.

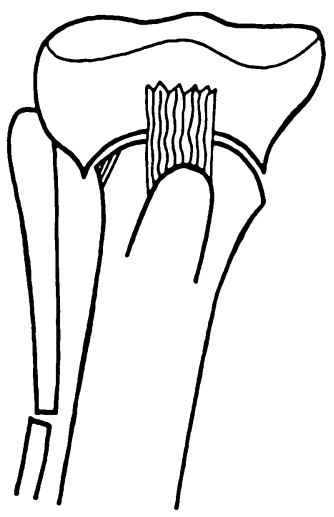

Fig. 4

Table I. The grading of pain and the number and percentage of knees in each grade before and after tibial osteotomy

\begin{tabular}{|c|c|c|c|c|c|c|c|c|}
\hline \multirow{3}{*}{$\begin{array}{l}\text { Pain } \\
\begin{array}{l}\text { Grade } 1 \\
\text { (severe) }\end{array}\end{array}$} & \multicolumn{4}{|c|}{$\begin{array}{l}\text { All cases } \\
\text { (105 knees) }\end{array}$} & \multicolumn{4}{|c|}{$\begin{array}{l}\text { Over } 5 \text { years' follow-up } \\
\text { (48 knees) }\end{array}$} \\
\hline & \multicolumn{2}{|c|}{ Before operation } & \multicolumn{2}{|c|}{ Follow-up } & \multicolumn{2}{|c|}{ Before operation } & \multicolumn{2}{|c|}{ Follow-up } \\
\hline & 53 & 50.5 & 6 & 5.7 & 27 & 56.3 & 4 & 8.3 \\
\hline $\begin{array}{l}\text { Grade } 2 \\
\text { (moderate, reducing activities or disturbing sleep) }\end{array}$ & 48 & 45.7 & 20 & 19.1 & 20 & 41.7 & 8 & 16.7 \\
\hline $\begin{array}{l}\text { Grade } 3 \\
\text { (mild, not interfering with activities or sleep) }\end{array}$ & 4 & 3.8 & 63 & 60 & 1 & 2.1 & 28 & 58.3 \\
\hline $\begin{array}{l}\text { Grade } 4 \\
\text { (none) }\end{array}$ & - & - & 16 & 15.2 & - & - & 8 & 16.7 \\
\hline
\end{tabular}

Kirschner wires or thin Steinmann pins are inserted parallel to each other on either side of the osteotomy site to help define the angular correction (Fig. 2). The osteotomy is then completed with a $15 \mathrm{~mm}$ osteotome (Fig. 3), care being taken to avoid over-penetration and damage to posterior nerves and vessels.

When the osteotomy is complete it can be rotated as shown in Figure 4 until the marker wires subtend the desired angle. The position is then secured with two or more staples. Check radiographs are not normally required. The wound is closed with drainage. A plaster cylinder is not always needed but may help provide stability for early weight-bearing. Active knee flexion can be encouraged once the wound has healed.

\section{MATERIAL AND METHODS}

The Royal National Orthopaedic Hospital has had a complete diagnostic coding system since 1948 with preservation of all radiographs. This was used with operation records to obtain details of all 122 patients who had had 140 upper tibial dome osteotomies in the previous 17 years. Of these patients, 13 had died and five were incapacitated from other causes, while 12 had been lost to follow-up. The 92 remaining patients with 105 osteotomies had been under the care of nine different surgeons and were all examined personally for this review.

The results were recorded on a standard form which included pre-operative data, operative technique, the patient's opinion and the findings on review. As far as possible we used the British Orthopaedic Association grading for knee arthroplasties (Aichroth et al. 1978). Standing anteroposterior and lateral radiographs were taken using $35 \mathrm{~cm}$ by $43 \mathrm{~cm}$ films and taking care that the patellae pointed forwards. Most of the pre-operative films had been taken standing using this method and we felt that other methods were unlikely to have given more reliable results, especially as more than $50 \%$ of the knees had a flexion deformity.

Follow-up was from a minimum of 12 months to 17 years (average 4.8 years). There was follow-up of over five years for 48 of the knees.

\section{RESULTS}

At the time of operation patients were from 38 to 79 years old (mean 64.2 years). Pain was the predominant symptom in all but four knees and was recorded in the four grades shown in Table I. It often restricted walking 

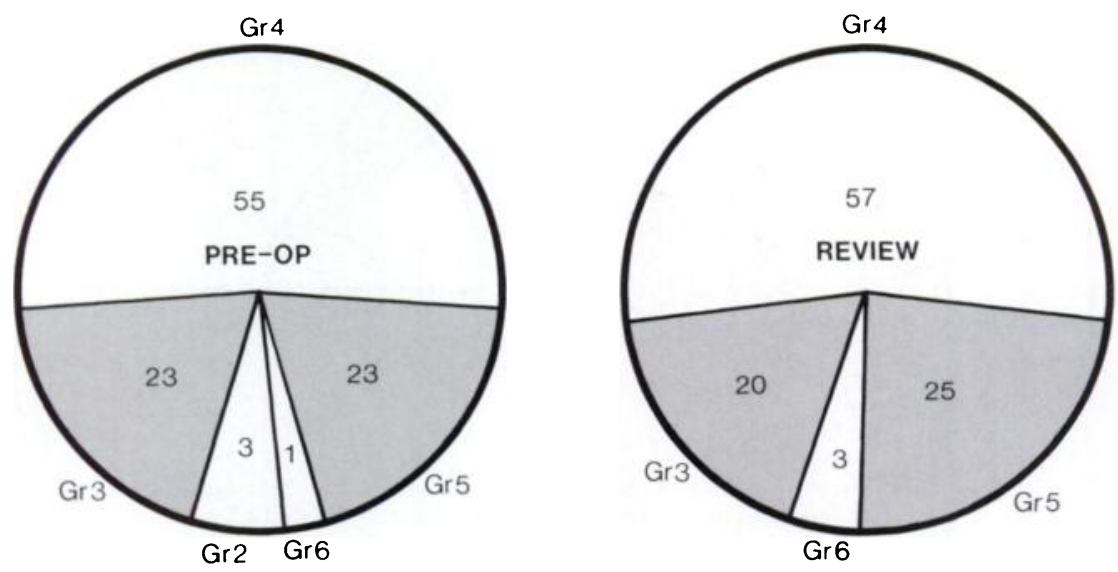

Fig. 5

Radiographic grading of tibiofemoral osteoarthritis before and after operation (see Table II for details of grades).

distance and disturbed sleep. Before operation $50.5 \%$ of knees gave continuous severe pain (Grade 1), but at follow-up only $5.7 \%$ had severe pain and $15.2 \%$ were completely free of pain.

We considered patients with our Grades 3 and 4 for pain to have good results, and this applied to $75.2 \%$ of the knees we reviewed. These figures refer to all 105 knees, with both valgus and varus deformities before operation. Only seven of these knees had had a valgus deformity and all seven had some relief of severe pain, one becoming pain-free, while five had mild and one moderate pain at follow-up. Two of these knees still showed some residual valgus deformity.

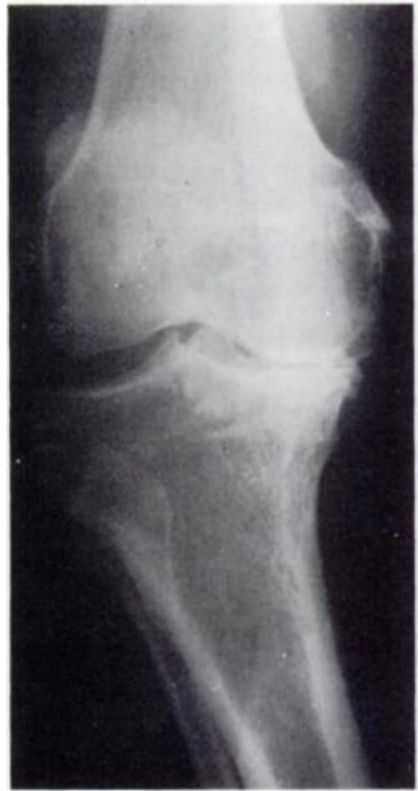

Fig. 6

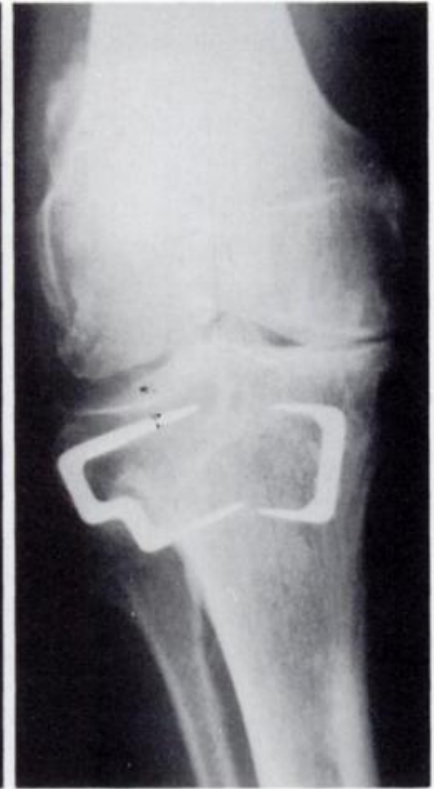

Fig. 7
Radiographs of the right knee of a 75-year-old man before and 2.5 years after osteotomy. The medial joint space is unchanged.
Walking distance had improved at follow-up though some patients were restricted by other painful joints. Fixed flexion was present in 54 knees $(51.4 \%)$ before operation and was unchanged by it. The range of flexion was also unchanged.

Patient's assessment. Of all patients $24.8 \%$ were enthusiastic about the result and another $48.6 \%$ were satisfied. All of these patients would have been willing to undergo a similar operation if they again developed their original symptoms. Non-committal replies were given by $10.5 \%$, and $16.2 \%$ were disappointed. Most of these had obtained some improvement of their symptoms, but they had expected complete relief of pain.

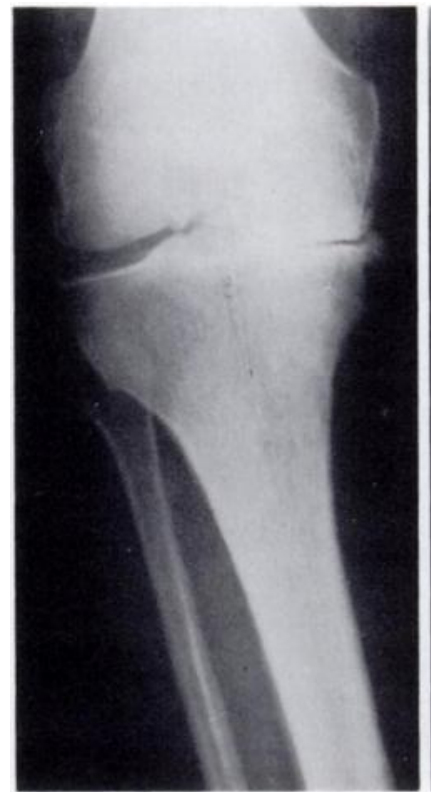

Fig. 8

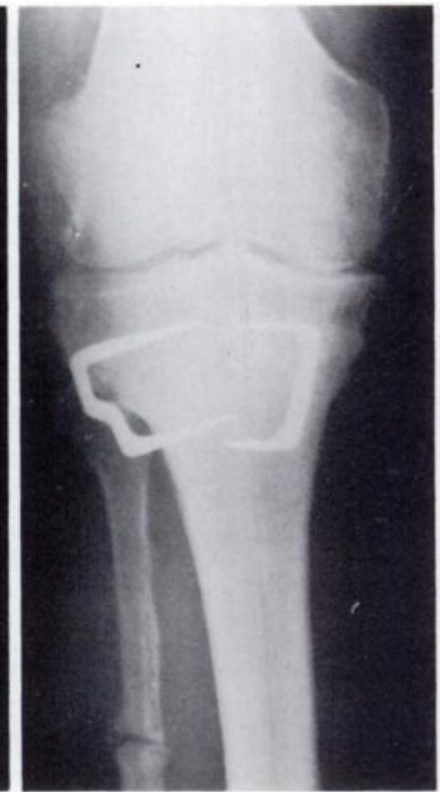

Fig. 9
Radiographs of the right knee of a 58-year-old woman before and 6 years after osteotomy. The medial joint space has improved. 

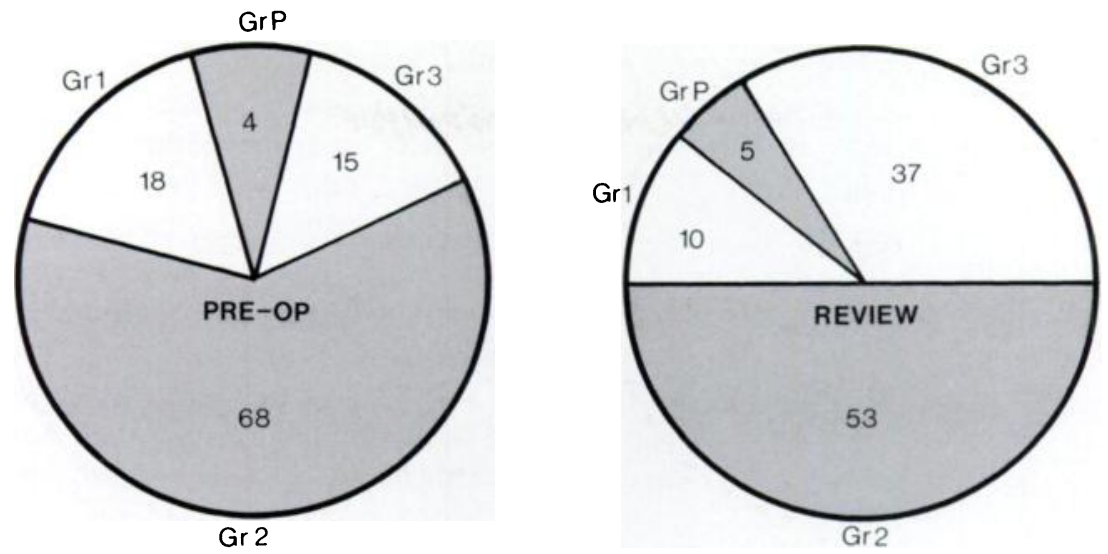

Fig. 10

Radiographic grading of patellofemoral osteoarthritis before and after operation (see Table II for details of grades).

Radiographic grading. We were unable to find a satisfactory grading method for radiographic changes in the osteoarthritic knee so we devised our own (Table II). We found only a slight tendency for progression of degenerative changes in the tibiofemoral compartments during follow-up (Fig. 5); some joints did not deteriorate at all (Figs 6 and 7). A few knees showed some regression of degenerative changes (Figs 8 and 9). There were similar patterns of change in the patellofemoral compartments (Fig. 10).

Correlation of result and alignment. The normal tibiofemoral angle has been variously reported to lie between $0^{\circ}$ and $15^{\circ}$ of valgus. Insall, Shoji and Mayer (1974) suggested $5^{\circ}$ to $15^{\circ}$, while Harding (1976) gave $0^{\circ}$ to $6^{\circ}$ after examining 40 normal knees. We took the commonly accepted figure of $7^{\circ}$ valgus as "normal", and

Table II. Radiographic grading of degenerative changes in osteoarthritis of the knee (see Figs 5 and 10)

\begin{tabular}{ll}
\hline Grade & Appearance \\
\hline $\begin{array}{l}\text { Tibiofemoral joint } \\
0\end{array}$ & Normal \\
1 & Normal joint space, small marginal osteophytes and cysts \\
2 & Normal joint space with marked sclerosis, osteophytes and cysts \\
3 & Loss of joint space but still more than $2 \mathrm{~mm}$ \\
4 & Joint space $2 \mathrm{~mm}$ or less \\
5 & No joint space or collapse of articular surface up to $0.5 \mathrm{~cm}$ \\
6 & Disorganised joint \\
Patellofemoral joint \\
0 & Normal \\
1 & Mild - slight narrowing with sclerosis and osteophytes \\
2 & Moderate - definite narrowing of joint space \\
3 & Severe - no joint space with advanced changes \\
P & Patellectomy \\
\hline
\end{tabular}

recorded those showing $5^{\circ}$ to $9^{\circ}$ as having a "good" correction.

In our series (Table III) only 18 of the 105 knees were in this range of $5^{\circ}$ to $9^{\circ}$ valgus at final review, and of these $77.8 \%$ had good results with pain grades 3 or 4 . Of the remaining 87 poorly corrected knees $74.7 \%$ had good results. Of the 48 knees followed-up for more than five years (Table IV) only five were well corrected; of these five, only three had good results, a smaller ratio than in the 43 poorly corrected knees.

The results are displayed in more detail in Table V, which shows a similar scatter of good and poor results whatever the final correction. This was also true for those with more than five years' follow-up (Table VI).

Table III. Correlation of pain and alignment in 105 knees

\begin{tabular}{lccccc}
\hline & \multicolumn{2}{l}{$\begin{array}{l}\text { Good correction } \\
(18 \text { knees) }\end{array}$} & & \multicolumn{2}{l}{$\begin{array}{l}\text { Poor correction } \\
(87 \text { knees })\end{array}$} \\
\cline { 2 - 3 } \cline { 5 - 6 } & Number & Per cent & & Number & Per cent \\
\hline Grade 1 (severe) & 1 & 5.6 & 5 & 5.7 \\
Grade 2 & 3 & 16.7 & 17 & 19.5 \\
Grade 3 & 10 & 55.6 & 53 & 60.9 \\
Grade 4 (none) & 4 & 22.2 & & 12 & 13.8 \\
\hline
\end{tabular}

Table IV. Correlation of pain and alignment in 48 knees followed up for more than 5 years

\begin{tabular}{lllllc}
\hline & \multicolumn{2}{l}{$\begin{array}{l}\text { Good correction } \\
\text { (5 knees) }\end{array}$} & & \multicolumn{2}{l}{$\begin{array}{l}\text { Poor correction } \\
\text { (43 knees) }\end{array}$} \\
\cline { 2 - 3 } \cline { 5 - 6 } & Number & Per cent & & Number & Per cent \\
\hline Grade 1 (severe) & 1 & 20 & & 7 \\
Grade 2 & 1 & 20 & & 16.3 \\
Grade 3 & 1 & 20 & & 27 & 62.8 \\
Grade 4 (none) & 2 & 40 & & 6 & 14.0 \\
\hline
\end{tabular}


Table V. Correlation of pain and alignment in 105 knees

\begin{tabular}{|c|c|c|c|c|c|c|}
\hline \multirow[b]{2}{*}{ Pain } & \multicolumn{2}{|l|}{ Varus } & \multicolumn{4}{|l|}{ Valgus } \\
\hline & Over $5^{\circ}$ & $5^{\circ}$ to $1^{\circ}$ & $0^{\circ}$ to $4^{\circ}$ & $5^{\circ}$ to $9^{\circ}$ & $10^{\circ}$ to $14^{\circ}$ & Over $14^{\circ}$ \\
\hline $\begin{array}{l}\text { Grade I } \\
\text { (severe) }\end{array}$ & 2 & 1 & 1 & 1 & - & 1 \\
\hline Grade 2 & 3 & 5 & 6 & 3 & 2 & 1 \\
\hline Grade 3 & 6 & 13 & 23 & 10 & 7 & 4 \\
\hline $\begin{array}{l}\text { Grade } 4 \\
\text { (none) }\end{array}$ & 4 & - & 5 & 4 & 2 & 1 \\
\hline
\end{tabular}

Table VI. Correlation of pain and alignment in 48 knees with more than 5 years' follow-up

\begin{tabular}{|c|c|c|c|c|c|c|}
\hline \multirow[b]{2}{*}{ Pain } & \multicolumn{2}{|l|}{ Varus } & \multicolumn{4}{|l|}{ Valgus } \\
\hline & Over $5^{\circ}$ & $5^{\circ}$ to $1^{\circ}$ & $0^{\circ}$ to $4^{\circ}$ & $5^{\circ}$ to $9^{\circ}$ & $10^{\circ}$ to $14^{\circ}$ & Over $14^{\circ}$ \\
\hline $\begin{array}{l}\text { Grade I } \\
\text { (severe) }\end{array}$ & 1 & 1 & - & 1 & - & 1 \\
\hline Grade 2 & 1 & 4 & 1 & 1 & - & 1 \\
\hline Grade 3 & 3 & 7 & 13 & 1 & 3 & 1 \\
\hline $\begin{array}{l}\text { Grade } 4 \\
\text { (none) }\end{array}$ & 3 & - & 3 & 2 & - & - \\
\hline
\end{tabular}

Complications. Three patients $(2.9 \%)$ developed deep vein thrombosis and three had pulmonary embolism. There were eight cases $(7.6 \%)$ of infection at the osteotomy site but all responded to antibiotic treatment. Delayed union was noted in six cases $(5.7 \%)$, three of which required bone grafting, though all united by eight months. Staples had to be removed for various reasons in nine cases $(8.6 \%)$.

Four tibial osteotomies failed $(3.8 \%)$. Two were revised to knee replacements for pain two and three years after osteotomy, their angulations being $7^{\circ}$ valgus and $6^{\circ}$ varus at the time of revision. One knee was arthrodesed six years after osteotomy having been in $8^{\circ}$ valgus. One revision osteotomy was performed.

There were complications from the fibular osteotomy in 15 cases $(14.3 \%)$. Three patients had weakness of extensor hallucis longus and four had paraesthesiae in the foot. There was troublesome bleeding at operation in three cases and five patients had persistent pain at the site of the fibular osteotomy.

\section{DISCUSSION}

Tibial osteotomy is an established treatment for osteoarthritis of the knee, aiming to relieve pain, correct deformity and improve function. The present study has confirmed it to be effective. The patients reviewed in this survey had good relief of pain : $80 \%$ had less pain, $44 \%$ by two or more grades; $19 \%$ had arrest of the progression of their pain and only one was made worse. Of the 48 knees followed up for more than five years, $75 \%$ had good results; this compares well with the results of Insall et al. (1974) who found $77 \%$ improvement in 51 knees at five years after wedge osteotomy.

Other authors have emphasised the need for accurate correction of deformity to provide good relief of pain and sustained benefit (Harris and Kostuik 1970; Maquet 1976). Over-correction by $5^{\circ}$ beyond the "normal" valgus is often advocated. In our series only 18 of 105 knees were in $5^{\circ}$ to $9^{\circ}$ valgus at follow-up, but despite this apparent failure to correct deformity many of the patients had good relief of pain. Analysis of the best and the worst results revealed no correlation between the amount of correction and the relief of pain.

Before operation $95.8 \%$ of the 98 knees originally in varus had moderate or severe pain compared with $25.5 \%$ after operation, the remainder having no pain or only mild pain. The results for the few knees in valgus before operation were equally good. With an average follow-up of 4.8 years we can report relief of pain for a useful period, and five of the nine patients with a follow-up of 10 years or more still had less pain than before operation, while two were completely pain-free.

Before we began this study we had the impression that dome osteotomy of the upper tibia was a good operation for osteoarthritis of the knee, bringing pain relief with few complications. Our results have confirmed this but we were surprised to find that accurate correction of deformity does not appear to be essential for relief of pain nor does the best correction give the best results. We cannot explain this but believe that it is a finding that merits further investigation.

\section{REFERENCES}

Aichroth P, Freeman MAR, Smillie JS, Souter WA. A knee function assessment chart. J Bone Joint Surg [Br] 1978;60-B:308-9.

Gunn AL. Results of treatment of painful deformed knee by upper tibial osteotomy. Guy's Hosp Rep 1969;118:293-306.

Harding ML. A fresh appraisal of tibial osteotomy for osteoarthritis of the knee. Clin Orthop 1976;114:223-4.

Harris WR, Kostuilk JP. High tibial osteotomy for osteo-arthritis of the knee. J Bone Joint Surg [Am] 1970;52-A :330-6.

Insall J, Shoji H, Mayer V. High tibial osteotomy: a five-year evaluation. J Bone Joint Surg [Am] 1974;56-A:1397-1405.

Jackson JP. Osteotomy for osteoarthritis of the knee. J Bone Joint Surg [Br] 1958;40-B:826.

Jackson JP, Waugh W. Tibial osteotomy for osteoarthritis of the knee. $J$ Bone Joint Surg [Br] 1961 ;43-B:746-51.

Jackson JP, Waugh W: The technique and complications of upper tibial osteotomy: a review of 226 operations. J Bone Joint Surg [Br] $1974 ; 56-B: 236-45$.

Krempen JF, Silver RA. Experience with the Maquet barrel-vault osteotomy. Clin Orthop 1982;168:86-96.

Magnuson PB, Stack JK. Fractures. 5th ed. Philadelphia etc:JB Lippincott 1949.

Maquet PGJ. Biomechanics of the knee with application to the pathogenesis and the surgical treatment of osteoarthritis. Berlin etc:Springer-Verlag, 1976.

Wardle EN. Osteotomy of the tibia and fibula in the treatment of chronic osteoarthritis of the knee. Postgrad Med J $1964 ; 40: 536-42$. 